\title{
DEVELOPMENT OF THE OPTIMIZATION MODEL OF THE INTERFACE OF MULTIMEDIA EDITION
}

\author{
Yevhen Hrabovskyi \\ Department of Computer Systems and Technologies \\ Simon Kuznets Kharkiv National University of Economics \\ 9-a Nauky ave., Kharkiv, Ukraine, 61166 \\ Yevhen.Hrabovskyi@hneu.net \\ Volodymyr Fedorchenko \\ Department of Information Systems \\ Simon Kuznets Kharkiv National University of Economics, \\ 9-a Nauky ave., Kharkiv, Ukraine, 61166 \\ fedorchenkofedor@gmail.com
}

\begin{abstract}
The aim of the research work is development of a model for optimizing the interface of a multimedia publication. In this research, five levels of interaction are identified for the interface of a multimedia publication - flat surfaces, layouts, structures, feature sets, strategies. The relationship between the levels of user interaction and interface properties of a multimedia publication is analyzed. It is proposed to select interface components based on the properties of the multimedia editions they provide.

In order to construct models of optimization of elements of the interface of a multimedia publication, estimates of the interconnection of elements of the interface with functional capabilities by the total matrix are used. To combine the standard models into a single interface optimization model, an analysis of the relationship between the elements of the interface of the multimedia publication and the characteristics of the multimedia publication has been conducted. According to the results of the analysis, an economical tree is constructed, which allows to build a hierarchy of the stages of optimization of the interface of the multimedia publication and to determine the input data for the implementation of the task. The definition of the input data allows to show the principle of the interface optimization model in the form of a "black" box.

An algorithm for optimizing the interface element of a multimedia publication is proposed. As a result of the practical implementation of the optimization model for the multimedia edition interface, a software product, created on the basis of HTML markup using cascading CSS style stylesheets and JavaScript language, was obtained. Adobe Device Central CS5 tested the created software on devices with different characteristics.
\end{abstract}

Keywords: multimedia edition, user interface, optimization model, total matrix.

\section{Introduction}

Multimedia editions are impressive in their diversity. There are many features that a multimedia edition should have. All of them are user-oriented. The user interface of the interface is a measure of the quality of the multimedia publication. Ease of use of a multimedia publication by the user provides the functionality of the interface. These features are related to the elements of the interface, which, depending on the wishes of the customer and the needs of the user, have certain functionality. The elements of the interface can be divided into groups depending on the main functions: graphic design, elements that are responsible for the way information is presented, controls.

Literary sources consider interface elements from different points of view. Often, the external representation of elements is considered, but the defined design rules are usually relative and have many examples that show the opposite [1-5]. However, besides the external presentation, the interface elements also have functionality. Functional capabilities allow to create interactive interfaces that can perform tasks provided by the user and provide information in a convenient form with the ability to control and adapt.

Since one of the features of multimedia interfaces is interactivity, functionality is a significant part of the presentation of the interface. Optimization of the interface of the multimedia edition by functionality increases the quality of the publication. 


\section{Materials and Methods}

The research methods are as follows. Analysis and synthesis are used at all stages of the study. The questionnaire is used to collect primary information about the main parameters of the interface of the multimedia publication. Expert estimation method - the method of pairwise comparisons is used to determine the importance of interconnections. Expert estimation method is used to highlight and determine the importance of interconnections based on the analysis of existing multimedia editions. The graph method - the economic tree is used to define the hierarchy of the development of the interface of the multimedia publication.

\section{Experimental procedures}

Jess Garrett highlights [2] five elements of the user experience and website experience. Since in this research work, the World Wide Web is considered as a software interface and hypertext information space, the levels set by Jess Garrett can be transferred to the interaction of the user - the multimedia interface, because the allocated levels are inherent to all electronic publications with a pronounced software interface using hypertext. This kind of electronic publications includes both multimedia editions.

Thus, for the interface of the multimedia edition, the following five levels of interaction are distinguished:

1) surface level. On the surface, the user sees a series of pages that contain certain content. Some content is interactive, the other simply informs the user about certain information;

2) layout level. Under the surface is the layout of the pages - the location of the functional elements and content. The layout is designed so that the organization of all elements is as effective and effective as possible;

3) level of structure. Layout is a concrete embodiment of the abstract structure of the site. For example, the layout specifies the position of the interface elements on the page, and the structure determines how users get to this page and where they can go. The layout defines the location of the navigation elements that allow users to move from one category to another, while the structure defines what is actually covered by these categories;

4) feature set level. The structure defines the way to organize different functionalities into a single whole. A simple listing of these features will create a level of set of capabilities;

5) strategy level. A set of opportunities is entirely determined by the strategy. The strategy includes what users want to get.

All levels of interaction are related to the properties of the interface of the multimedia edition. Schematically, the transition from user interaction levels and multimedia editions to the properties of the multimedia edition interface is shown in Fig. 1.

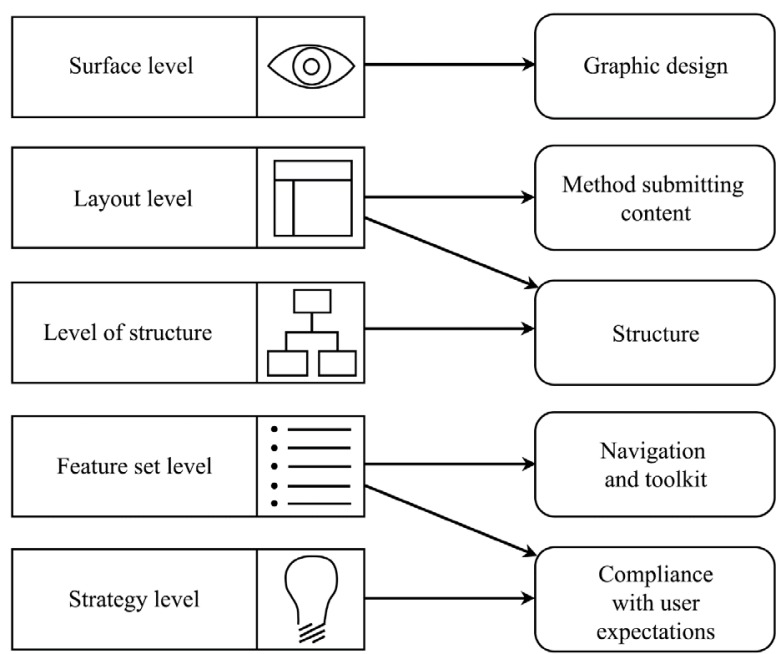

Fig. 1. The relationship between the levels of user interaction and the properties of the interface of the multimedia publication 
Each property of the interface of a multimedia publication can be compared to a number of elements of the interface (Table 1). The isolation of the components was based on the analysis of literary sources [6-10] and existing multimedia publications.

Table 1

Allocation of interface components based on the features of the multimedia editions they provide

\begin{tabular}{cc}
\hline Feature & Interface Component \\
\hline Graphic design (d) & Color (d1) \\
Font (d2) & Screen typography (d3) \\
Sethod of the content feed (k) & Screensaver (k1) \\
& The main content: text, image, audio, video, game, etc. (k2) \\
Interactivity (f1)
\end{tabular}

The isolation of interactions between elements of the interface of the multimedia publication and their functional capabilities was conducted by expert evaluation. As experts, 10 managers of such leading multimedia publishing houses and web-studios of Ukraine as Artjoker, Nextpage, WID7, Karagez, Brainlab, Sitepark, and Lantrix spoke. The selection of experts was carried out by means of a mutual evaluation of the competency of the applicants during the sociometric survey (Table 2) - the most effective method of group evaluation.

Table 2

Results of sociometric survey

\begin{tabular}{|c|c|c|c|c|c|c|c|c|c|c|c|c|}
\hline \multirow{2}{*}{ Who was selected } & \multicolumn{10}{|c|}{ Was selected by } & \multirow{2}{*}{$\begin{array}{l}\text { Number of } \\
\text { selections }\end{array}$} & \multirow{2}{*}{ Expert rank } \\
\hline & 1 & 2 & 3 & 4 & 5 & 6 & 7 & 8 & 9 & 10 & & \\
\hline 1 expert & 1 & & 1 & & 1 & & 1 & & 1 & 1 & 6 & 1 \\
\hline 2 expert & & 1 & 1 & & & 1 & & 1 & & & 4 & 2 \\
\hline 3 expert & 1 & & & 1 & 1 & & 1 & & 1 & 1 & 6 & 1 \\
\hline 4 expert & & 1 & 1 & & & 1 & & 1 & & & 4 & 2 \\
\hline 5 expert & & & & & 1 & & 1 & 1 & & & 3 & 3 \\
\hline 6 expert & 1 & 1 & & 1 & & 1 & & & 1 & 1 & 6 & 1 \\
\hline 7 expert & & & 1 & 1 & & 1 & 1 & & & & 4 & 2 \\
\hline 8 expert & 1 & 1 & & & 1 & 1 & 1 & & 1 & & 6 & 1 \\
\hline 9 expert & 1 & & 1 & 1 & & & & 1 & 1 & 1 & 6 & 1 \\
\hline 10 expert & & 1 & & 1 & 1 & & & 1 & & & 4 & 2 \\
\hline Total selection & 5 & 5 & 5 & 5 & 5 & 5 & 5 & 5 & 5 & 4 & & \\
\hline
\end{tabular}


The survey resulted in the selection of 5 experts who received the highest rank and are the most competent in the field of developing interfaces for multimedia editions.

The selected expert group was asked to analyze the existence of links between the interface elements and functionality in multimedia editions. If the interface element has functionality in the list, then the presence of the link is noted, if not - the connection is absent. Thus, the dichotomy method has highlighted the existence of links between elements of interfaces and functional capabilities.

To assess the consistency of experts, the variance of the preferences of experts is determined and the frequency matrix of the preferences of experts is constructed (Table 3). Since dichotomy uses only two response options ( 0 and 1$)$, the frequency matrix of the preferences of experts is also a summary matrix reflecting the opinions of all experts.

Table 3

A total matrix reflecting the opinions of all experts

\begin{tabular}{|c|c|c|c|c|c|c|c|}
\hline Interface components & f1 & f2 & f3 & f4 & f5 & Sum & Dispersion \\
\hline $\mathrm{d} 1$ & 0 & 3 & 5 & 2 & 0 & 10 & 4,5 \\
\hline $\mathrm{d} 2$ & 0 & 1 & 5 & 3 & 0 & 9 & 4,7 \\
\hline d3 & 0 & 0 & 5 & 0 & 0 & 5 & 5 \\
\hline $\mathrm{k} 1$ & 4 & 2 & 5 & 0 & 0 & 11 & 5,2 \\
\hline $\mathrm{k} 2$ & 5 & 4 & 5 & 4 & 3 & 21 & 0,7 \\
\hline $\mathrm{n} 1$ & 4 & 3 & 5 & 0 & 4 & 16 & 3,7 \\
\hline $\mathrm{n} 2$ & 3 & 1 & 5 & 0 & 0 & 9 & 4,7 \\
\hline n3 & 4 & 0 & 5 & 0 & 0 & 9 & 6,2 \\
\hline n4 & 3 & 0 & 5 & 0 & 0 & 8 & 5,3 \\
\hline n5 & 3 & 2 & 5 & 3 & 1 & 14 & 2,2 \\
\hline n6 & 5 & 0 & 5 & 2 & 0 & 12 & 6,3 \\
\hline
\end{tabular}

The dispersion of the importance of interconnections in each case of comparison is not lower than 0.3 , which indicates the normality of their distribution and the coherence of expert responses.

\section{Results}

Since the developer is interested in optimizing the interface of a multimedia publication, the interface optimization model should provide him with an assessment of alternatives developed by the developer, and suggest ways to optimize the interface when analyzing one alternative.

Therefore, in order to optimize the interface of a multimedia publication, it is necessary for each of the elements of the interface of the multimedia publication to develop a normative model of its evaluation.

Normative interface model is designed to find the desired optimal interface design. Its construction should provide six steps:

1) selection of criteria of optimality;

2) determining the relative weight of each criterion;

3) a list of all possible alternatives;

4) evaluation of alternatives for each parameter;

5) a summary together for a comparative analysis of estimates of all alternatives in all parameters;

6) a choice of the alternative with the best indicator under item 5.

To construct models of optimization of the elements of the interface of the multimedia publication, we use the estimates of the interrelations of the elements of the interface with the functional capabilities by the total matrix (Table 3), highlighted at the preliminary stage of the study 
The criteria for each interface element will be selected as functionality. Based on these estimates, we calculate the weight of each criterion by the formula:

$$
\mathrm{W}_{\mathrm{i}}=\frac{\mathrm{O}_{\mathrm{i}}}{\sum \mathrm{O}_{\mathrm{i}}}
$$

where $\mathrm{W}_{\mathrm{i}}$ - the weight of the $\mathrm{i}$-th criterion; $\mathrm{O}_{\mathrm{i}}-$ evaluation of the $\mathrm{i}$-th criterion; $\sum \mathrm{O}_{\mathrm{i}}-$ sum of ratings for this element of the multimedia editions interface.

To combine the standard models into a single interface optimization model, we will analyze the relationship between the elements of the interface of the multimedia publication and the characteristics of the multimedia publication. Based on this analysis we put an estimate that will serve as the length of the rib for constructing the graph (Table 4) as follows: 5 - if the relation is not considered in literary sources, but is available in analyzed publications (not all); 4 - not considered in literary sources, but is available in analyzed publications; 3 - is considered in literary sources, but not observed in the analyzed publications; 2 - is considered in literary sources, but is not observed in all analyzed publications; 1 - is considered in literary sources and is available in analyzed editions.

\section{Table 4}

Estimation of the ratio of components of the multimedia interface and characteristics of the multimedia publication

\begin{tabular}{|c|c|c|c|c|c|c|c|}
\hline $\begin{array}{c}\text { Interface } \\
\text { components }\end{array}$ & Publication & $\begin{array}{l}\text { Style of } \\
\text { design }\end{array}$ & Topics & $\begin{array}{l}\text { The gender of } \\
\text { the user }\end{array}$ & $\begin{array}{l}\text { The age of } \\
\text { the user }\end{array}$ & $\begin{array}{l}\text { Distribution } \\
\text { method }\end{array}$ & $\begin{array}{c}\text { Representative } \\
\text { systems }\end{array}$ \\
\hline $\mathrm{d} 1$ & 2 & 1 & 4 & 3 & 3 & - & - \\
\hline $\mathrm{d} 2$ & 2 & 1 & - & - & 2 & 3 & - \\
\hline $\mathrm{d} 3$ & - & - & - & - & - & - & - \\
\hline $\mathrm{k}$ & 4 & - & - & - & 2 & - & 1 \\
\hline $\mathrm{n} 1$ & - & - & - & - & - & - & - \\
\hline $\mathrm{n} 2$ & 4 & - & - & - & - & - & - \\
\hline n3 & - & - & - & - & - & 1 & - \\
\hline $\mathrm{n} 4$ & - & - & - & - & - & 3 & - \\
\hline $\mathrm{n} 5$ & - & - & - & - & - & 5 & - \\
\hline n6 & - & - & 4 & - & - & - & - \\
\hline
\end{tabular}

Based on the data we build graph (Fig. 2), taking into account the relationship with the customer (length of ribs 1):

1) customer - the type of publication;

2) customer - design style;

3) customer - the subject;

4) customer - to become a user;

5) customer - the age of the user;

6) customer - representative systems;

7) customer - on-screen typography;

8) customer - search;

9) customer - structure.

Symbols to be used when working with a graph:

$\mathrm{x} 0$ - customer; $\mathrm{x} 1$ - type of publication; $\mathrm{x} 2$ - style of design; $\mathrm{x} 3$ - topics; $\mathrm{x} 4$ - become a user; $\mathrm{x} 5$ - the age of the user; $\mathrm{x} 6$ - method of distribution; $\mathrm{x} 7$ - representative systems; $\mathrm{x} 8$ - the structure of the publication; $\mathrm{x} 9$ - color scheme; $\mathrm{x} 10$ - font; $\mathrm{x} 11$ - on-screen typography; $\mathrm{x} 12$ - the way of submitting content; x13 - search; x14 - hypertext; x15 - URL; x16 - duplicate navigation; x17 - menu; x18 - other controls; x19 - icons; x20 - CUA; x21 - an alternative representation. 
According to this graph, we build an economic tree (Fig. 3). In the beginning, choose the edge of the minimum length $\mathrm{d} 01=1$. At each next step, choose the next minimum edge, ensuring that no loop is formed.

The economic tree allows to build a hierarchy of the stages of optimization of the interface of the multimedia edition. From the economic tree it is evident that during the receipt of data from the customer determined: the type of publication; the presence of a corporate or other style of design; subjects, characteristics of the user: gender, age, representative systems, which will be targeted edition; method of distribution, structure; way of presenting an on-screen typography; availability of a search and a way to present other controls.

At the next stage, based on the data of the previous stage of the study, the color scheme of the publication, fonts, content delivery, hypertext, URL, menu, icons, CUA and alternative representation of navigation elements and a set of tools are allocated. The final stage includes the representation of duplicate navigation.

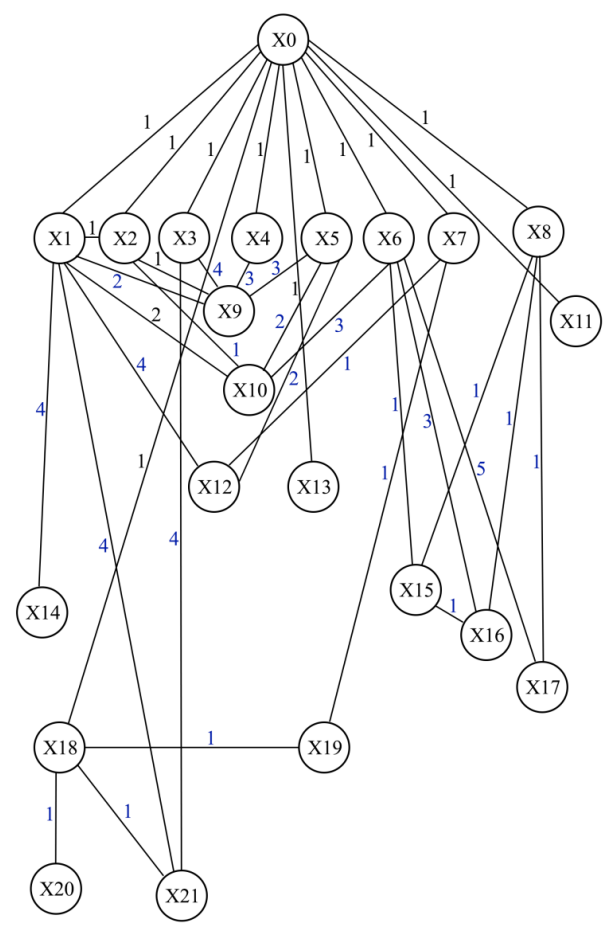

Fig. 2. A graph representing the interfaces between the interface elements and the characteristics of the multimedia publication

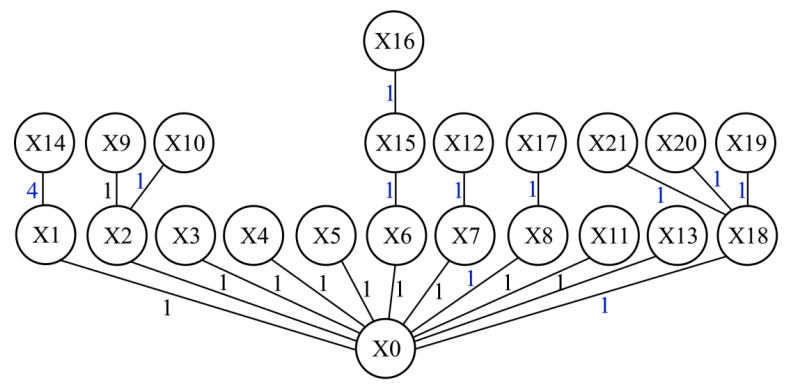

Fig. 3. An economic tree optimizing the interface of the multimedia edition

Thus, the construction of an economical tree allowed to build a hierarchy of development of the interface of the multimedia edition. The data obtained in the first level of the hierarchy are independent of each other, but depending on the wishes of the customer (zero level), the data of the second and third levels of the hierarchy depend on the data of the first level. 
Also, an economical tree shows which data are input for the model optimization of the interface of the multimedia edition. The definition of the input data allows us to show the principle of the interface optimization model in the form of a "black" box (Fig. 4).

\begin{tabular}{|c|c|c|}
\hline & $\begin{array}{l}\text { Criteria for } \\
\text { optimizing } \\
\text { interface } \\
\text { elements }\end{array}$ & $\begin{array}{c}\text { Interface } \\
\text { optimization } \\
\text { criteria }\end{array}$ \\
\hline Type of publication & \multirow{11}{*}{$\begin{array}{l}\text { Multimedia } \\
\text { Edition } \\
\text { Interface } \\
\text { Optimization } \\
\text { Model }\end{array}$} & \multirow{6}{*}{$\begin{array}{l}\text { Assessment of } \\
\text { the completeness } \\
\text { of the use of } \\
\text { the functionality } \\
\text { of the interface } \\
\text { elements }\end{array}$} \\
\hline Design style & & \\
\hline Theme & & \\
\hline User sex & & \\
\hline User age & & \\
\hline $\begin{array}{l}\text { The way of representing } \\
\text { other controls }\end{array}$ & & \\
\hline Representative systems & & \multirow{5}{*}{$\begin{array}{l}\text { Assessment of } \\
\text { the completeness } \\
\text { of the use of } \\
\text { multimedia } \\
\text { interface } \\
\text { functionality }\end{array}$} \\
\hline Structure & & \\
\hline Mode of distribution & & \\
\hline Search availability & & \\
\hline $\begin{array}{l}\text { The way to present } \\
\text { screen typography }\end{array}$ & & \\
\hline
\end{tabular}

Fig. 4. The model of optimization of the interface of a multimedia publication in the form of a "black" box

Optimization of interface elements is performed after determining the design and functionality of the element.

\section{Discussion}

For practical implementation of the model, a program must be created that, depending on the criteria selected by the user, will give an assessment of the completeness of the use of functionality. The software product should be able to analyze the completeness of the use of functionality not only the interface as a whole, but also its individual elements.

The regulatory model involves comparing several alternatives in the process of optimization. Therefore, in order to analyze the degree of optimization of the interface of a multimedia publication, it should be possible to compare the alternative variants of presentation of the elements of the interface. Today in the specialized literature [1-10] there is no algorithm for the process of optimizing the interface element of the multimedia publication.

To solve the problem of automation of the process of optimization of interface elements, an algorithm for analysis of the interface element (Fig. 5) was developed, which includes the following steps:

1) entering user data about available functionality of the interface element;

2) selection of criteria corresponding to the functionality for this element of the interface;

3) calculation of the product data entered by the user on the weight of the criteria;

4) calculation of the assessment of the completeness of the functionality of the interface of the multimedia publication, by determining the amount of products obtained in the previous stage.

The sequence of execution of the above stages of the algorithm is transformed into corresponding links between the blocks in Fig. 5.

Conditional symbols in Fig. 5 are:

$\mathrm{A}[\mathrm{n}]$ - the array of $\mathrm{i}$ data about the available functionality of the interface element;

$\mathrm{B}[\mathrm{n}]$ - the array of criteria corresponding to the functionality for this element of the interface;

$c[i]$ - the product data entered by the user, the weight of the criteria, $i=\overline{0, n}$.

As a result of the practical implementation of the optimization model for the multimedia edition interface, a product created on the basis of HTML markup was obtained. Cascading stylesheets CSS 3 were used for registration, the program part is written in JavaScript language. This combi- 
nation allowed the development of a software product that can be used either over the Internet or without a network connection. The file of the resulting product is very small in size. A fragment of the script that describes the contents of the developed software product is shown in Fig. 6.

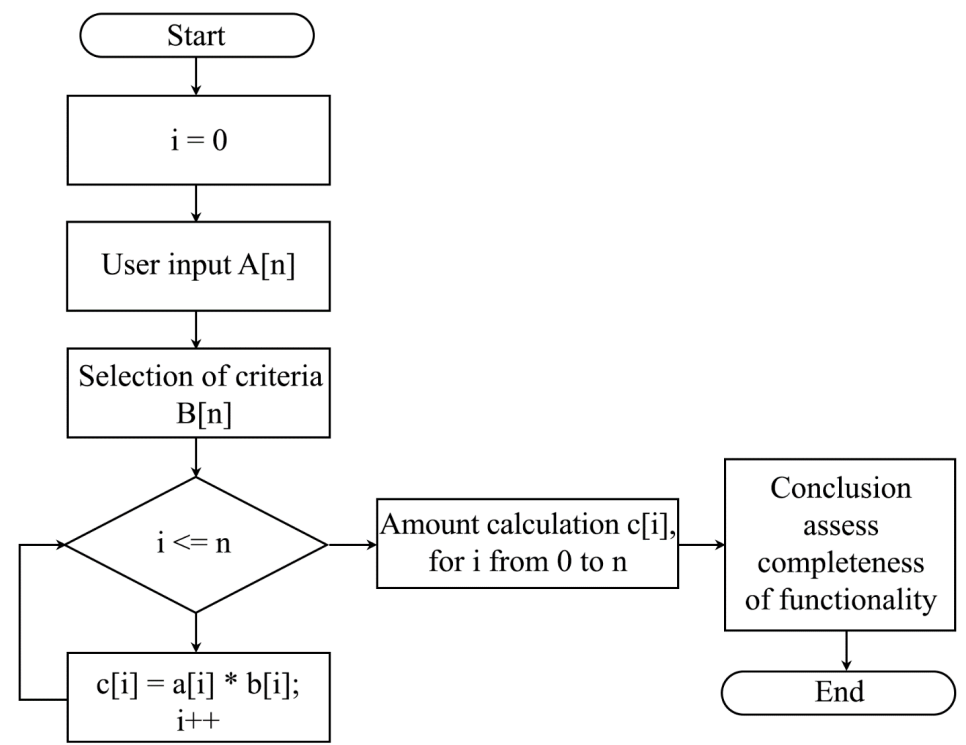

Fig. 5. Block diagram of the process of optimizing the elements of the interface of the multimedia edition

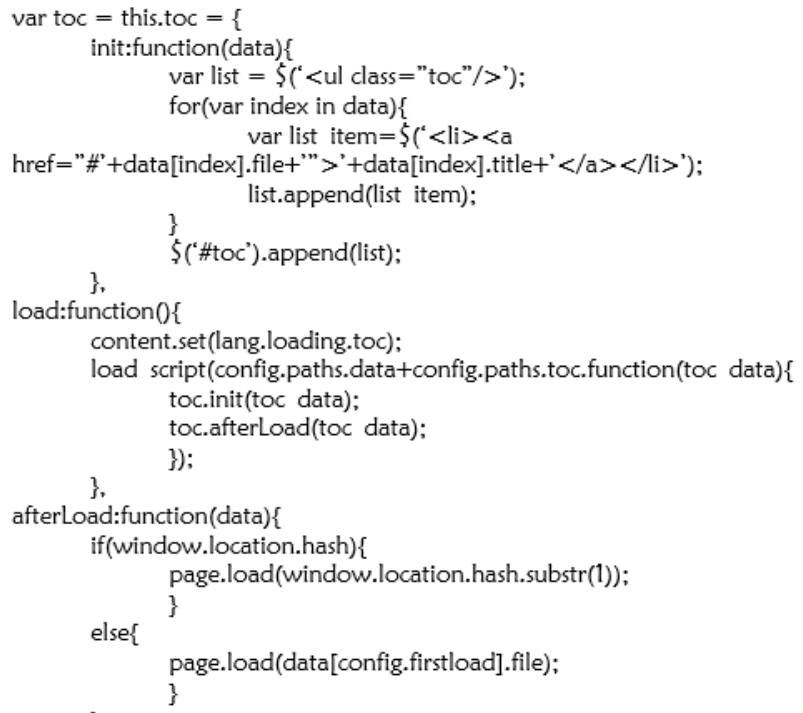

Fig. 6. Content module script

The screenshot of the interface for optimizing the multimedia edition is shown in Fig. 7.

Testing the created software on devices with different characteristics was done using Adobe Device Central CS5.

By adapting the software product to a specific browser, we will understand the correctness of the display of the main elements of the interface of a software product in a particular browser.

The results of using the software in Opera and Chrome browsers are shown respectively in Fig. 8, 9.

Test results show that the developed product is most adapted to Opera and Chrome browsers, so it is better to use it through these browsers. 


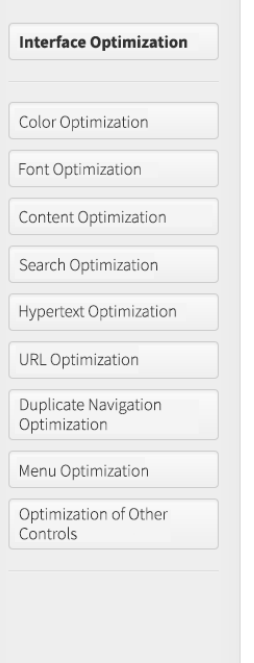

\begin{tabular}{|c|c|c|c|}
\hline \multicolumn{4}{|c|}{ Interface Optimization } \\
\hline \multicolumn{4}{|c|}{ Color Scheme } \\
\hline 0,00 & Control Capability & 0,00 & Monotony \\
\hline 0,00 & Adaptation & & \\
\hline \multicolumn{4}{|l|}{ Fonts } \\
\hline 0,00 & Control Capability & 0,00 & Monotony \\
\hline 0,00 & Adaptation & & \\
\hline \multicolumn{4}{|c|}{ Screen Typography } \\
\hline 0,00 & Monotony & & \\
\hline
\end{tabular}

Content Presentation

Screen Saver

\begin{tabular}{ll}
\hline 0,00 & Interactivity $\quad 0,00$ Control Capability \\
0,00 & Monotony \\
Main Content
\end{tabular}

Fig. 7. Rich Media Interface Optimization Page

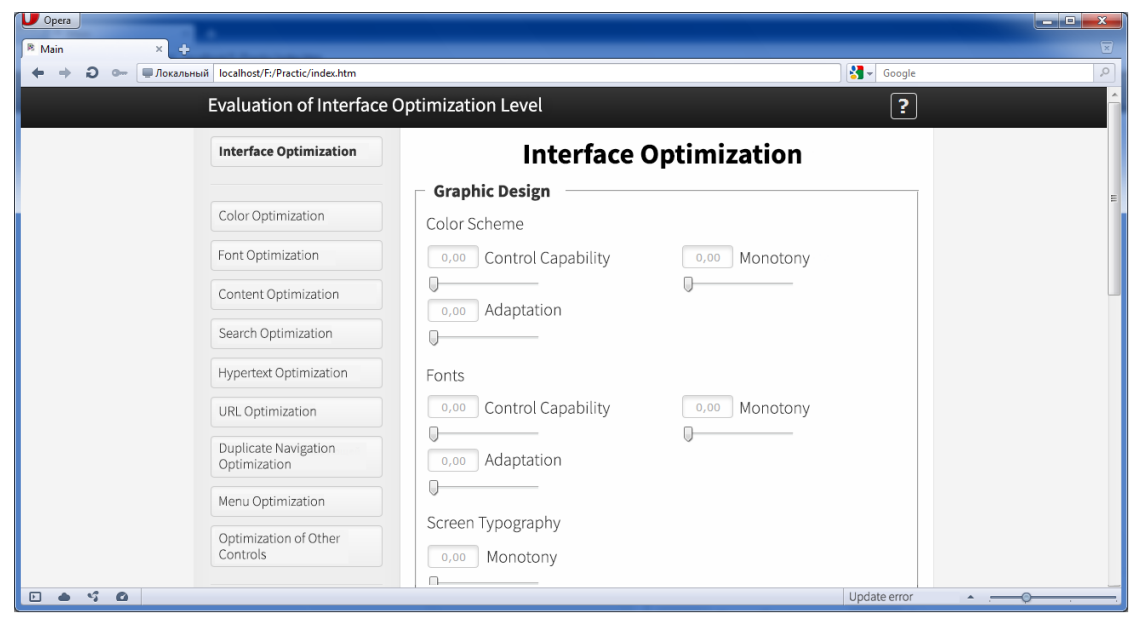

Fig. 8. The result of testing the software product in the browser Opera

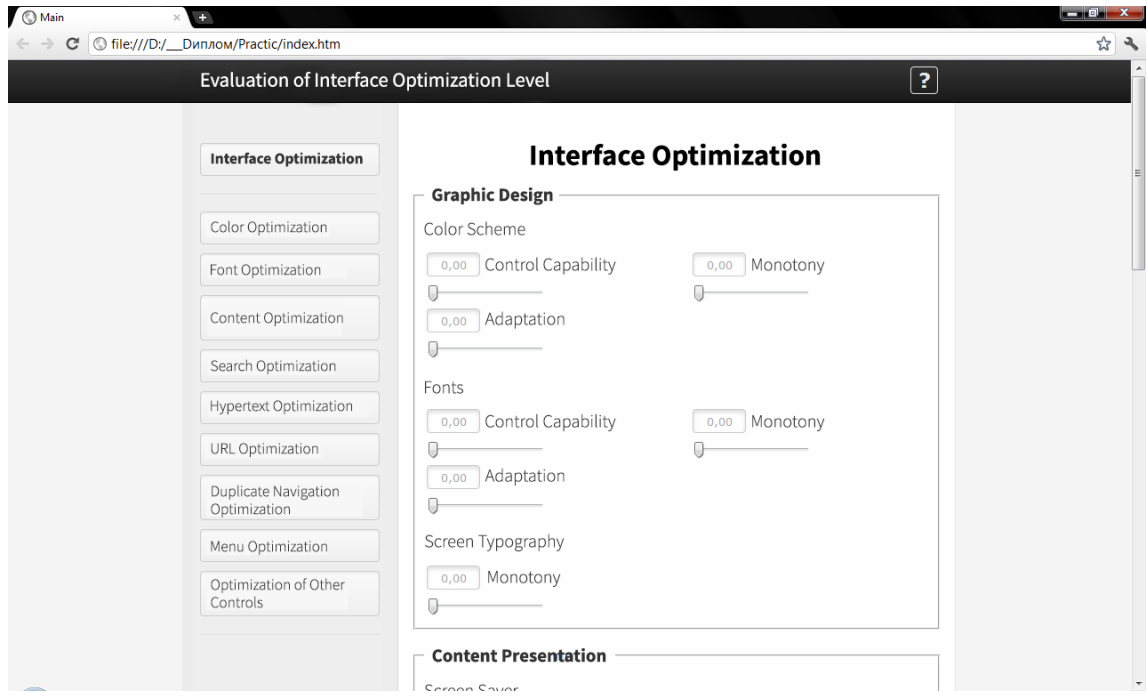

Fig. 9. The result of testing the software in Chrome browser 


\section{Conclusions}

Thus, as a research result, a model for optimizing the interface of a multimedia publication was developed, which provides the most complete use of all available functionality as an interface to the multimedia publication as a whole, as well as to its individual elements. Using this model facilitates the choice of the necessary method for presenting the interface element and its functionality and ways to optimize it.

This study allows to highlight ways to optimize the functionality of the interface of the multimedia edition. The results of this study can be used in the design of multimedia interfaces both at the design stage to support decision-making, as well as to analyze the degree of optimization of the functionality of the already developed edition.

\section{References}

[1] Aralova, N. I., Kyiashko, O. Y. (2017). The Method of Technology Evaluation Based on Improved Cost Approach. Science and Innovation, 13 (3), 65-76. doi: https://doi.org/10.15407/scine13.03.065

[2] Garrett, J. (2003). The Elements of User Experience: User-centered Design for the Web. San Francisco: New Riders, 168.

[3] Hrabovskyi, Y., Yevsyeyev, O., Pandorin, A. (2018). Development of a method for the creation of $3 \mathrm{~d}$ advertising printing products. Eastern-European Journal of Enterprise Technologies, 6 (2 (96)), 6-18. doi: https://doi.org/10.15587/1729-4061.2018.147325

[4] Naumenko, M., Hrabovskyi, Y. (2018). Elaboration of methodology for designing a publishing and printing web portal. Eastern-European Journal of Enterprise Technologies, 2 (2 (92)), 14-22. doi: https:// doi.org/10.15587/1729-4061.2018.126305

[5] Hood, N. (2016). Quality in MOOCs: Surveying the terrain. Burnaby: Commonwealth of Learning, 40.

[6] Hryshchuk, R., Molodetska, K. (2016). Synergetic Control of Social Networking Services Actors' Interactions. Advances in Intelligent Systems and Computing, 34-42. doi: https://doi.org/10.1007/9783-319-48923-0_5

[7] Martins, P. V., Zacarias, M. (2017). A Web-based Tool for Business Process Improvement. International Journal of Web Portals, 9 (2), 68-84. doi: https://doi.org/10.4018/ijwp.2017070104

[8] Brambilla, M., Fraternali, P. (2014). Large-scale Model-Driven Engineering of web user interaction: The WebML and WebRatio experience. Science of Computer Programming, 89, 71-87. doi: https:/doi. org/10.1016/j.scico.2013.03.010

[9] Kuisma, J., Hyönä, J., Simola, J. (Eds.) (2015). Perception of visual advertising in different media: from attention to distraction, persuasion, preference and memory. Lausanne: Frontiers Media SA, 124. doi: https://doi.org/10.3389/978-2-88919-416-2

[10] Hu, C., Zhao, Y., Guo, M. (2009). AHP and CA Based Evaluation of Website Information Service Quality: An Empirical Study on High-Tech Industry Information Center Web Portals. Journal of Service Science and Management, 02 (03), 168-180. doi: https://doi.org/10.4236/jssm.2009.23020 